\title{
Modeling Spatial Distribution of 2D Anisotropic Hydraulic Conductivity Tensor of Fractured Groundwater Flow Media using Neural Network \\ Case Study Grasberg Open Pit of PTFI and Surrounding
}

\author{
Postgraduate Student, Mining Engineering, ITB ${ }^{1,2}$ \\ Lecturer, Mining Engineering, ITB ${ }^{3}$ \\ Manager, Grasberg Geo service PTFI ${ }^{4}$
}

AdamVerdyansyahPutra ${ }^{* 1}$,TedyAgungCahyadi ${ }^{2}$, LilikEkoWidodo ${ }^{3}$, and EmanWidijanto ${ }^{4}$

\begin{abstract}
Highly fractured rocks in Grasberg open pit and surrounding of PT Freeport Indonesia (PTFI) result in fractured groundwater flow media. It is due to the complex geological structure and lithological condition. Accordingly, it leads to anisotropic distribution of hydraulic conductivity. The paper will be devoted tothe modeling of two dimensional (2D) spatial distribution of hydraulic conductivity using neural network. Surface fracture mapping database will be used to estimate 2D equivalent anisotropic hydraulic conductivity tensor based on the Oda et al (1996) approach. Modeled anisotropic hydraulic conductivity is then checked at some points where the slug tests for isotropic conductivity are observed. Co-relation, validation and training between modeled and observed hydraulic conductivity is then carried out using transformation of vector anisotropic hydraulic conductivity into the scalar isotropic hydraulic conductivity. Following training step, neural network will then generate two dimensional model of anisotropic hydraulic conductivity distribution. It is beneficial for modeling of shallow anisotropic flow of groundwater distribution.
\end{abstract}

Index Terms- hydraulic conductivity tensor, modeling two dimensional distribution, neural network (NN), Oda method

\section{INTRODUCTION}

PT Freeport Indonesia which is located in Mimika, West Papua Province, Indonesia is one of the largest mining company in indonesia. One of the problem that happen in Grasberg is the present of groundwater that will affect slope stability and mud rush.

Hidraulic conductivity in fractured rock media is important to predict the flow direction of water. Every fracture has its own characteristic which are apperture, lenght, deep, orientation, (RQD), fruekuency and density of fracture. The characteristic above may result in anisotropic, vectoral as well as tensoral hydraulic conductivity.

\section{METHOD}

The absolute hydraulic conductivity will be calculated according to Oda etal (1996) in which flow media is modeled as a pair of paralel lines. This geometric description have caracteristics as follow:

- Each line has a length $l$.

- Fracture aperture $(e)$ is defined as a distance (opening) between the parallel lines and taken to be constant.

- The position of parallel lines is characterized by the coordinate of their end points in the planar media.
- The parallel lines have orientation in planar media corresponding to the normal vector ofeach line.

Hydraulic conductivity tensoric absolut can be expressed in numerical as follow

$$
K_{i j}=\frac{1}{12 X Y} \sum_{k=1}^{k=m} l_{k} e_{k}^{3} \cos \left(\theta_{k}\right) \sin \left(\theta_{k}\right)
$$

Whereas :

$\mathrm{m}$ : sumation Index

$\mathrm{K}$ : tensoric absolute permeability

$\mathrm{N}$ : Number of fracture

$l, e:$ lenght and apperture of fracture

$\mathrm{X}, \mathrm{Y}$ : Normal in $\mathrm{X}$ and $\mathrm{Y}$ axes

\section{$\theta \quad$ : Orientation}

To create surface model, neural network will be used to predict tensoric hydraulic conductivity. Neural network enables information processing is performed at different layers, dividing network nodes into three categories, input nodes, output nodes and hidden nodes. Input nodes do not perform calculations, while output and hidden nodes are computational nodes.The output node values are the final numerical outputs of the network.

\section{DATA AND CALCULATION}

\subsection{Data Preparation}

This paper uses secondary data that is obtained by Geotech and Geology Division PTFI, 2014 using scanline in Grasberg Open Pit mine site surface. Structure data consists of 51,040 points with apperture, lenght of fracture, coordinate, elevation and orientation as its properties. Also, this paper uses 13 drill holes in which hydraulic conductivity value is observed using slugtest.

\subsection{Anisotropic Hydraulic Conductivity Calculation}

Corelation between Kscalar and Kslugtest also $\mathrm{K}_{\mathrm{xy}}$ and $\mathrm{K}_{\text {slugtest }}$ is created in scatter plot to figure the connection between 2 data. Corelation in scatter plot shows that coefficient of corelation in this two data are 0.742 and 0.773 respectively which means the calculation using Oda method is accurately enough. Also, the corelation between $\mathrm{K}_{\mathrm{xy}}$ and $\mathrm{K}_{\text {slugtest }}$ shows that the flow of ground water follows the path of major structure which is North East. Above is the scatter plot that shows coefficient of corelation. 


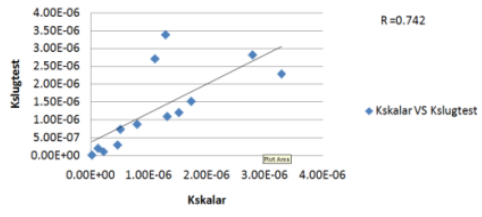

Fig.1. Corelation between $\mathrm{K}_{\text {scalar }}$ and $\mathrm{K}_{\text {slugtest }}$

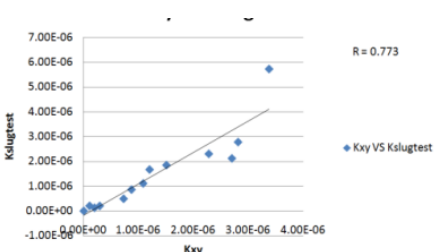

Fig.2. Corelation between $\mathrm{K}_{\text {scalar }}$ and $\mathrm{K}_{\text {slugtest }}$

\subsection{Neural Network Process}

Neural network structure is cosntructed from input data which consist of apperture, lenght of fracture, orientation, coordinate, and elevation. To optimize the result of neural network, number of results are selected. This selection process based on the cross-validation and mean squared error.Above is the result of layer optimation

TABLE I

SUMMARY OF LAYER OPTIMATION

\begin{tabular}{|c|c|c|}
\hline Hydraulic & MSE & Optimum \\
\hline Conductivity & Value & Layer \\
\hline kxx & $1.73 \mathrm{E}-15$ & 12 \\
\hline kyy & $4.87 \mathrm{E}-15$ & 11 \\
\hline kxy & $1.76 \mathrm{E}-14$ & 9 \\
\hline
\end{tabular}

By using this optimation in neural network, distribution of anisotropic hydraulic conductivity can be generated using apperture, length of fracture, orientation and Rock Quality Designation (RQD) as input data. Figure above shows hydraulic conductivity in $\mathrm{K}_{\mathrm{xx}}, \mathrm{K}_{\mathrm{yy}}$, and $\mathrm{K}_{\mathrm{xy}}$.

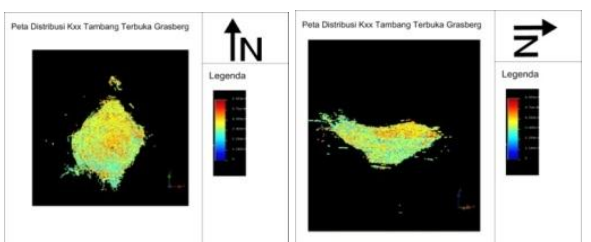

Fig 3. Distribution of hydraulic conductivity $\mathbf{K}_{\mathrm{xx}}$

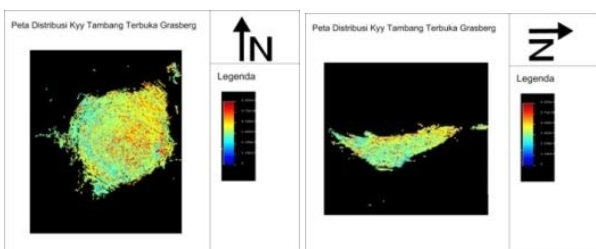

Fig.4 Distribution of hydraulic conductivity $\mathrm{K}_{\mathrm{yy}}$

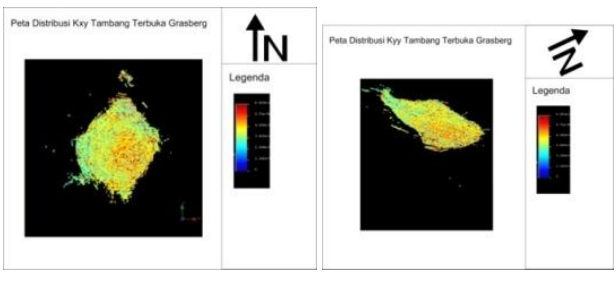

Fig.5. Distribution of hydraulic conductivity $\mathrm{K}_{\mathrm{xy}}$

\section{ANALYSIS AND DISCUSSION}

4.1 Corelation of RQD and geological condition with Data

The blue color shows low RQD value, while the red color shows high RQD value. There is corelation between RQD and hydraulic conductivity value. From the figure shown above, area with low RQD value is concentrated in West, East and Northe East area. By this condition we can conclude that there is a corelation between RQD and hydraulic conductivity. The least RQD value will result in high hydraulic conductivity value.

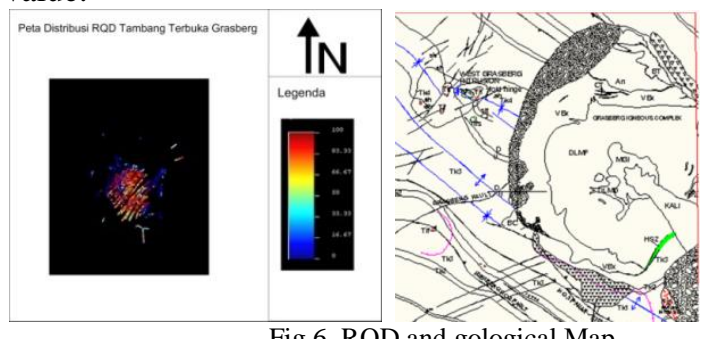

Fig.6. RQD and gological Map

For the next part, From the geological map shown above we can conclude the reason why hydraulic conductivity value high in 'East, West, and North East Grasberg area. First, The East and North east area of Grasberg have high hydraulic conductivity due to Kali Formation and continuity from Grasberg Fault to North east from South west. Secondly, in West area the cross section of Grasberg Fault and Idenberg 1 fault create fractured area that result to high hydraulic conductivity value.

\section{ACKNOWLEDGMENT}

The authors gratefully acknowledge the contributions PTFI as give permit for used the data.

\section{REFERENCES}

[1] Oda, M., Kanamaru, M., and Iwashita, K.,. "The Effect of Crack Geometry on Hydrodynamic Dispersamanion in Cracked Media. Soils and Foundations", Japanese Geotechnical Society(1996), Vol. 36, No. 2, h. 69-80.

[2] ASCE Task Committee on Application of Artificial Neural Networks in Hydrology (2000) Artificial neural networks in hydrology. II BioComp System

[3] HCI, "Hydrogeologic Model and Groundwater Flow Modeling of Grasberg”. Internal Report(2003), PT. Freeport Indonesia, not published.

[4] PTFI, "Grasberg and Soroundings Geological Condition". Internal Report (1999), PT Freeport Indonesia, not published.

[5] Grasberg GeoservisGeotech, Hydrology, and Geology Division PT FI, "Geology Structure and Hydrology Measurement". Internal Report(2014),not published.

[6] Widodo et al .,Two phase permeability and capillarity pressure of two-dimensional fracture network in geological media., (2003)., JTM 